Research Article

\title{
Effect of -O- on Water Molecule Adsorption and Adsorption Mechanism of Lignite and Coke
}

\author{
Xue Bai, ${ }^{1}$ Yue Yin Song, ${ }^{1}$ Ying Yue Teng $\mathbb{D}^{1,2}$ Wen Lu Zhang, ${ }^{1}$ Yin Min Song, \\ and Yun Fei Wang $\mathbb{D}^{3}$ \\ ${ }^{1}$ College of Chemical Engineering, Inner Mongolia University of Technology, Huhhot 010051, China \\ ${ }^{2}$ Inner Mongolia Key Laboratory of High-Value Functional Utilization of Low Rank Carbon Resources, \\ Inner Mongolia University of Technology, Huhhot 010051, China \\ ${ }^{3}$ College of Chemical Engineering, Ordos Institute of Technology, Ordos 017000, China \\ Correspondence should be addressed to Ying Yue Teng; tengyingyue@163.com and Yun Fei Wang; yunfeiwang111@126.com
}

Received 31 January 2021; Revised 31 August 2021; Accepted 13 September 2021; Published 21 October 2021

Academic Editor: Jae Ryang Hahn

Copyright ( $\odot 2021$ Xue Bai et al. This is an open access article distributed under the Creative Commons Attribution License, which permits unrestricted use, distribution, and reproduction in any medium, provided the original work is properly cited.

\begin{abstract}
The high moisture content of lignite restricts its extensive and efficient use. Furthermore, the reabsorption of lignite is also a factor that affects lignite spontaneous combustion. Therefore, it is of great importance to study the process and mechanism of water molecule desorption and adsorption on lignite and coke $\left(25-950^{\circ} \mathrm{C}\right)$ to achieve the clean and efficient utilization of lignite and environmental protection. Proton nuclear magnetic resonance $\left({ }^{1} \mathrm{H}-\mathrm{NMR}\right)$, thermogravimetric analysis, and other techniques were used in this study to explore the water molecule absorption and desorption processes of lignite pyrolysis at different temperatures $\left(25-950^{\circ} \mathrm{C}\right)$ and the special contributions of ether bonds to water molecule adsorption. A mechanism of lignite water molecule adsorption was proposed. The results showed that ether bonds played a special role in the water molecule adsorption by pyrolyzed lignite. The ether bond content was greater in the coal samples at 300 and $950^{\circ} \mathrm{C}$, which changed the trend of lignite water molecule absorption and the distribution of water $\left(T_{2}\right)$ detected in the ${ }^{1} \mathrm{H}$-NMR experiments and delayed the escape of water molecules during moisture desorption. The total amount of adsorbed water decreased first and then increased in the coal samples as the pyrolysis temperature increased. However, the maximum adsorption interactions of each coal sample increased first and then decreased. This was the result of the interactions between the pores and the oxygen-containing functional groups. Based on the above analysis, water molecule adsorption mechanism models of lignite and coke were constructed. This study offers a new approach for investigating the water molecule adsorption and adsorption mechanisms of lignite and coke.
\end{abstract}

\section{Introduction}

The energy crisis is becoming more and more serious around the world. Lignite is an important coal reserve. However, owing to its high moisture content, low heat value, easy weathering, and spontaneous combustion, the utilization efficiency of lignite is relatively low [1]. At present, the common method to improve the utilization efficiency is lignite upgrading, but the current technologies fail to solve the problems of moisture adsorption and spontaneous combustion of lignite [2].

The microstructural and adsorption characteristics of lignite have been the focus of many scholars. Tao et al. [3] compared the material composition, pore structure, and adsorption capacity of lignite and candle coal and found that lignite has a higher inertinite content, larger pore volume, better connectivity, and greater specific surface area (SSA) than candle coal. In another article, a continuous distribution model of pore space was constructed for coal reservoirs based on the measured data of mercury intrusion porosimetry (MIP) and low-temperature nitrogen adsorption (LTNA) experiments. This model can obtain the complete pore size distribution from nanopores to microfractures [4]. Series and parallel seepage simulations of coal matrix pore samples, natural fracture samples, and artificial fracture samples with three permeability ranges were designed and performed [5]. Another analysis showed that after water immersion, the content of hydroxyl and aromatic 
hydrocarbons in the coal increased significantly, and the temperature at which fat-based and oxygen-containing functional groups participated in the reaction decreased [6]. The monolayer water in soft brown coal comprises only about one twentieth of the total water present, and it is attached to coal by hydrogen bonds in suitable polar functional groups [7]. Gutierrez-Rodriguez et al. [8] estimated the hydrophobicity of coal. In recent years, the research on this subject has focused more on the adsorption effect of the functional groups on water. Liu et al. [9] suggested that the potential to form more hydrogen bonds is the key factor influencing the interaction energy between model compounds and water molecules. The behavior of water in coal depends on many factors, such as intermolecular hydrogen bonding [10]. Water molecules interact with the oxygen-containing functional groups on the surface of coal by hydrogen bonds [11-14]. The research on the moisture adsorption of lignite has mainly focused on the water occurrence state and the influence of $-\mathrm{OH}, \mathrm{C}=\mathrm{O}$, and other functional groups [7, 15-17]. However, there are few studies on the effect of a single functional group, such as -O-, on water molecule adsorption in the existing literature.

In this study, the pore distribution, the effect of oxygencontaining functional groups on water molecule adsorption, and the relationship between the oxygen-containing functional groups, pores, and water molecule adsorption were examined [18]. Based on previous studies, the influence of ether bonds on the water molecule adsorption in lignite and coke $\left(<950^{\circ} \mathrm{C}\right)$ was investigated through proton nuclear magnetic resonance $\left({ }^{1} \mathrm{H}-\mathrm{NMR}\right)$ and water molecule absorption and desorption experiments to lay a foundation for the inhibition of lignite reabsorption and spontaneous combustion.

\section{Method}

All of the data obtained in this experiment were collected through three parallel experiments, and their average values were calculated and reported as the final values.

2.1. Sample Preparation. Lignite samples were collected from the Shengli Mine of China. The coal samples were crushed and screened, and those with particle sizes of 200-400 mesh were stored for future use. Raw coal was stored directly at room temperature $\left(25^{\circ} \mathrm{C}\right)$, and other coal samples were extracted by pyrolysis in a fixed-bed reactor. Coal samples were selected and heated to $50,75,105,200$, $300,500,700$, and $950^{\circ} \mathrm{C}$ at $5^{\circ} \mathrm{C} / \mathrm{min}$ under a nitrogen atmosphere for $1 \mathrm{~h}$. The obtained sample was labeled with the corresponding temperature, and the temperature label of the raw coal (untreated coal sample) was $25^{\circ} \mathrm{C}$. Table 1 displays the results of the proximate and ultimate analyses of all coal samples obtained by an industrial analyzer (5E-MAG6700), an element analyzer (5E-CHN2000), and an infrared sulfur meter (5E-IRS II).

2.2. Moisture Adsorption and Desorption. The moisture adsorption experiments were performed in an SHBY-40B standard curing box (manufactured by Jiangsu Wuxi Southern China Experimental Instrument Inc.). The coal samples were spread on a $35 \mathrm{~mm}$ culture dish, which was then placed into a constant-temperature $\left(30^{\circ} \mathrm{C}\right)$ and constant-humidity (85\%) box. The first $6 \mathrm{~h}$ was divided into three phases, with $2 \mathrm{~h}$ for each phase and an interval of $30 \mathrm{~min}$. The samples were weighed every 1 or $2 \mathrm{~h}$. Equilibrium moisture adsorption was reached if the difference between the two adjacent weights was smaller than $0.01 \mathrm{~g}$. The adsorption of water and the equilibrium adsorption ratio were calculated as follows:

$$
\begin{array}{r}
\text { adsorption of water }=m_{t}-m_{0}, \\
\text { equilibrium adsorption ratio }=\frac{\left(m_{t}-m_{0}\right)}{m_{0} \times 100 \%},
\end{array}
$$

where $m_{0}$ is the mass of the lignite sample and $m_{t}$ is the mass of the lignite sample after water absorption.

Lignite and coke samples after the adsorption of water molecules were desorbed with a temperature rise rate of $2^{\circ} \mathrm{C} /$ min and a temperature range of $25-200^{\circ} \mathrm{C}$. A thermogravimetric analyzer was used to obtain the thermogravimetry (TG), derivative thermogravimetry (DTG), and differential thermal analysis (DTA) curves of the desorbed lignite after adsorption.

2.3. Proton Nuclear Magnetic Resonance ( ${ }^{1} H$-NMR). ${ }^{1}$ H-NMR (VTMR20-010V-T; Shanghai Niumag) was performed to test the water contents of the samples. The testing parameters were a resonance frequency of $21.306 \mathrm{MHz}$, magnetic intensity of $0.5 \mathrm{~T}$, coil diameter of $10 \mathrm{~mm}$, and a magnetic temperature of $35.00^{\circ} \mathrm{C}$. The sample signal values were collected using NMR analysis software, and Carr-Purcell-Meiboom-Gill (CPMG) sequences were obtained. On this basis, the $T_{2}$ spectrum was obtained through inversion with the simultaneous iterative reconstruction technique (SIRT). The coal samples (1-1.25 g) were placed into a detector oven, and the detection limit of water was $10 \mathrm{mg}$.

The coal samples were immersed in water for $24 \mathrm{~h}$ under standard conditions to fill all the pores with water such that they became saturated water samples. The coal samples were placed in an environment with a specified humidity, and water was adsorbed to the surface of the lignite. This kind coal sample is called an adsorbed water sample.

The interaction strength between the lignite and water molecules is expressed as a transverse relaxation time $T_{2}$ (ms), as follows [19]:

$$
M_{x y}=M_{0} \times \exp \left(\frac{-t}{T_{2}}\right),
$$

where $M_{x y}$ is the component of the macroscopic magnetization vector on the $x-y$ axis, $M_{0}$ is the initial magnetization vector, and $T_{2}$ is the transverse relaxation time. The interaction strength $M_{x y}$ is related to the relaxation time $t$ by equation (2). 
TABle 1: Proximate and elemental analysis results of raw coal.

\begin{tabular}{|c|c|c|c|c|c|c|c|c|c|}
\hline \multirow{2}{*}{ Lignite $\left({ }^{\circ} \mathrm{C}\right)$} & \multicolumn{4}{|c|}{ Proximate analysis (wt\%) } & \multicolumn{5}{|c|}{ Ultimate analysis $(\mathrm{wt} \%, \mathrm{~d})$} \\
\hline & $M_{a d}$ & $A_{d}$ & $V_{d}$ & $\mathrm{FC}_{d}$ & $\mathrm{C}$ & $\mathrm{H}$ & $\mathrm{O}^{*}$ & S & $\mathrm{N}$ \\
\hline 25 & 25.28 & 12.80 & 34.57 & 52.63 & 61.79 & 4.49 & 18.95 & 1.21 & 0.76 \\
\hline 50 & 17.68 & 12.87 & 34.20 & 52.93 & 62.00 & 4.31 & 18.88 & 1.19 & 0.75 \\
\hline 75 & 8.58 & 12.66 & 34.95 & 52.39 & 61.74 & 4.27 & 19.39 & 1.19 & 0.75 \\
\hline 105 & 1.52 & 12.90 & 35.00 & 52.10 & 62.10 & 4.12 & 18.98 & 1.17 & 0.73 \\
\hline 200 & 1.23 & 13.10 & 33.72 & 53.18 & 61.94 & 3.87 & 18.88 & 1.36 & 0.85 \\
\hline 300 & 1.10 & 14.75 & 28.18 & 57.07 & 61.62 & 3.42 & 17.66 & 1.64 & 0.91 \\
\hline 500 & 0.60 & 17.04 & 15.90 & 67.06 & 69.38 & 2.57 & 8.70 & 1.27 & 1.04 \\
\hline 700 & 0.62 & 19.01 & 7.59 & 73.41 & 73.32 & 1.69 & 3.43 & 1.42 & 1.13 \\
\hline 950 & 0.47 & 18.50 & 3.58 & 77.93 & 75.12 & 1.10 & 2.41 & 2.50 & 0.37 \\
\hline
\end{tabular}

ad/d/daf: air-dried/dried/dried ash-free basis; A: ash content; V: volatile content; FC: fixed carbon; O*: by difference.

2.4. Oxygen-Containing Functional Groups. Oxygen-containing functional groups were tested using Fourier-transform infrared spectroscopy (FTIR, NEXUS670; American Nicolet Corporation). The $\mathrm{KBr}$ method was performed to prepare the samples. The samples and $\mathrm{KBr}$ were mixed at a ratio of $1: 120$. Infrared spectra were obtained within the range of $400-4000 \mathrm{~cm}^{-1}$, and the scanning time was set at $25 \mathrm{~s}$. The resolving power and wavenumber accuracy were 0.125 and $0.001 \mathrm{~cm}^{-1}$, respectively. The calculation of the content of oxygen-containing functional groups is shown in Supplementary Materials S1.

2.5. Microstructure of Lignite Coke. The specific surface areas and pore distributions of the coal samples were determined by a low-temperature nitrogen adsorption method using a 3H-2000PS2 tester from the Baystar Instrument Technology (Beijing) Co., Ltd. The Brunauer-Emmett-Teller (BET) and Barrett-Joyner-Halenda $(\mathrm{BJH})$ methods were used to calculate the specific surface area, pore volume, and pore distribution for each sample. The surface morphologies and particle sizes of the coal samples were observed using scanning electron microscopy (SEM, s-3400N, Hitachi company). The accelerating voltage was $20 \mathrm{kV}$, and backscattered electron imaging was performed.

\section{Results and Discussion}

\subsection{Abnormal Changes of Moisture Absorption and Desorption in Lignite}

3.1.1. Moisture Content of Coal Samples after Equilibrium Adsorption in Difference Method. In this study, we found that under conditions with a constant temperature of $30^{\circ} \mathrm{C}$ and humidity of $85 \%$ and after the coal samples absorb water to achieve equilibrium adsorption, the moisture content of coal samples decreased first and then increased with the increase in treatment temperature (Figure 1). The moisture content of raw coal at $25^{\circ} \mathrm{C}$ is the highest, reaching $26.44 \%$. The moisture content of heat-treated coal sample at $105^{\circ} \mathrm{C}$ was higher than that at $75^{\circ} \mathrm{C}$, which may be due to the exposure of functional groups after the escape of water molecules with strong binding force. Comparing Figure 1 with Table 1, we can see that the coal sample heat treated at $105^{\circ} \mathrm{C}$ achieved a maximum adsorption rate of $22.80 \%$. At

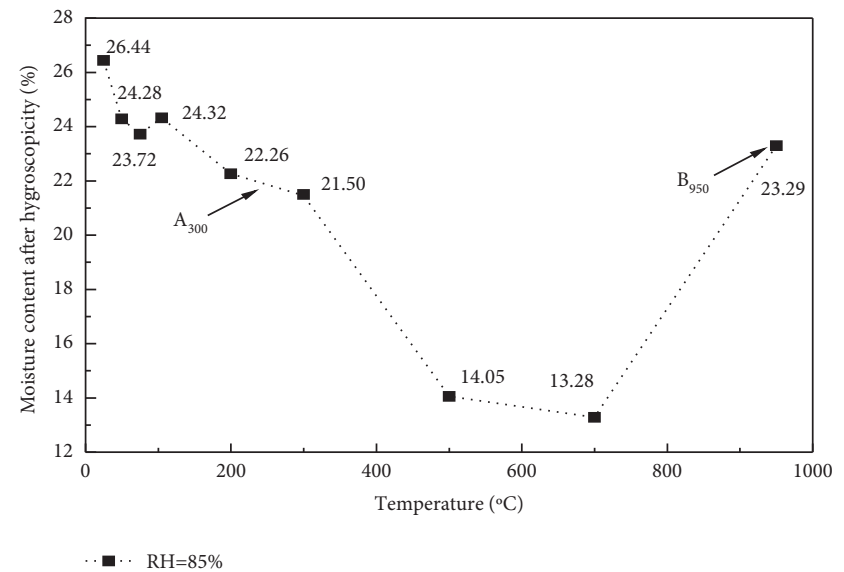

FIGURE 1: Moisture content of the heat-treated coal samples after equilibrium adsorption in differential method.

higher heat-treatment temperatures, the adsorption rate decreased. In the $200-300^{\circ} \mathrm{C}$ range, the coal sample equilibrium adsorption rate was relatively low, and at $700^{\circ} \mathrm{C}$, the heat-treated coal sample equilibrium adsorption rate was the lowest, with a value of $12.66 \%$, and the moisture content was $13.28 \%$. At $950^{\circ} \mathrm{C}$, the equilibrium adsorption rates of the coal samples increased up to $22.82 \%$, and the moisture content was $23.29 \%$. The moisture adsorption capacities of the coke at 300 and $950^{\circ} \mathrm{C}$ were abnormal as well (Figure 1: $A_{300}$ and $\left.B_{950}\right)$.

3.1.2. Moisture Content of Coal Samples after Equilibrium Adsorption in ${ }^{1} H$-NMR Analysis. Table 2 shows the $T_{2}$ distribution and spectral intensity of the equilibrium adsorbed water. The total water content $\left(A_{\text {total }}\right)$ decreased with the increase in the temperature below $700^{\circ} \mathrm{C}$. The water content of the coal sample increased at $950^{\circ} \mathrm{C}$ (Figure 2).

When the heat-treatment temperature of the coal sample was lower than $105^{\circ} \mathrm{C}$, the total amount of adsorbed water $\left(A_{\text {total }}\right)$ of the coal sample decreased with the increase in the heat-treatment temperature (Table 2 and Figure 2). This is similar to the trend in Figure 1. However, the coal sample heated at $105^{\circ} \mathrm{C}$ showed its particularity, which may be caused by its strong binding force with water molecules after the exposure of the functional group, which cannot be detected by 
TABle 2: Amplitude (AU) and distribution of $T_{2}$ spectra of moisture adsorption of the SLH.

\begin{tabular}{lcccc:c}
\hline Temperature $\left({ }^{\circ} \mathrm{C}\right)$ & $T_{21} / \mathrm{ms}$ & $A_{21}\left(\times 10^{3}\right)$ & $A q\left(\times 10^{2}\right)$ & $A_{\text {total }}\left(\times 10^{3}\right)$ \\
\hline 25 & 0.76 & 3.15 & 0.6 & 3.21 \\
50 & 0.75 & 3.09 & 0.66 & 3.16 \\
75 & 0.65 & 3.12 & 0.42 & 3.16 \\
105 & 0.37 & 2.5 & 0.24 & 2.52 \\
200 & 0.28 & 2.16 & 1.22 & 2.28 \\
300 & 0.27 & 1.92 & 1.07 & 2.03 \\
500 & 0.18 & 1.3 & 2.72 & 1.57 \\
700 & 1.32 & 1.54 & 0.1 & 1.55 \\
950 & 3.05 & 1.75 & 6.29 & 2.38 \\
\hline
\end{tabular}



FIgURE 2: Moisture content of the heat-treated coal samples after equilibrium adsorption in ${ }^{1} \mathrm{H}-\mathrm{NMR}$ analysis.

${ }^{1} \mathrm{H}-\mathrm{NMR}$. When the heat-treatment temperature was $105-700^{\circ} \mathrm{C}$, the amount of adsorbed water decreased, the rate of decrease of the amount of adsorbed water of the coal sample heated at $300^{\circ} \mathrm{C}$ slowed (Figure 2: $A_{300}$ ), and the amount of adsorbed water of the coal sample heated at $950^{\circ} \mathrm{C}$ increased sharply (Figure 2: $B_{950}$ ). With the increase in the heat-treatment temperature, the coal samples for heat treatment at 300 and $950^{\circ} \mathrm{C}$ showed abnormal moisture adsorption.

3.1.3. Water Desorption. The TG curves of the water desorption from lignite after adsorption were obtained by desorption experiments (Figure 3 ). The amount of desorbed water of raw coal $\left(25^{\circ} \mathrm{C}\right)$ after water absorption was the largest, approaching $20 \%$. As the pyrolysis temperature of lignite increased, the amount of desorbed water of lignite decreased gradually. The amounts of desorbed water of the coal samples treated at 50,75 , and $105^{\circ} \mathrm{C}$ were almost the same, and those of the coal samples treated at 300 and $950^{\circ} \mathrm{C}$ were abnormal. The amount of desorbed water of the coal sample treated at $300^{\circ} \mathrm{C}$ was greater than that of coal sample treated at $200^{\circ} \mathrm{C}$, and the amount of desorbed water of the coal sample treated at $950^{\circ} \mathrm{C}$ was greater than that of coal sample treated at $500^{\circ} \mathrm{C}$, which was consistent with the results of the adsorption process described above (Figures 1 and 2).

The corresponding DTA (Figure 4) and DTG (Figure 5) data were further analyzed. Most of the adsorbed water was removed at $80^{\circ} \mathrm{C}$. Small amounts of water in the coal samples at 300 and $950^{\circ} \mathrm{C}$ needed more energy to release from the sample surfaces, and the removal temperature was around $100^{\circ} \mathrm{C}$. Strong binding interactions occurred in the coal samples heated at $300^{\circ} \mathrm{C}$, similar to that in the coal samples heated at $950^{\circ} \mathrm{C}$.

In the moisture absorption and desorption experiments of lignite coke, with the increase in the heat-treatment temperature, the equilibrium amount of adsorbed water of the coal coke increased first $\left(<105^{\circ} \mathrm{C}\right)$, then decreased $\left(105-700^{\circ} \mathrm{C}\right)$, and then increased dramatically $\left(700-950^{\circ} \mathrm{C}\right)$. At the same time, the coal samples for heat treatment at 300 and $950^{\circ} \mathrm{C}$ showed abnormal moisture adsorption behaviors. Water desorption experiments showed that some of the water in the coal samples for heat treatment at 300 and $950^{\circ} \mathrm{C}$ was difficult to remove, and the water had relatively stronger bonds.

3.2. State of Adsorbed Water Occurrence. ${ }^{1} \mathrm{H}-\mathrm{NMR}$ was used to investigate the differences in the state of adsorbed water under saturated and unsaturated conditions. The primary moisture adsorbed on the surfaces of the lignite and coke was detected by ${ }^{1} \mathrm{H}-\mathrm{NMR}$, and the peak shifts of the adsorption curves were used to show the main binding interaction. Figure 6 shows the water molecule adsorption capacities of the coke samples with different degrees of pyrolysis. When the treatment temperature was below $500^{\circ} \mathrm{C}$, the relaxation time $\left(T_{2}\right)$ moved to the left as the temperature increased (curve a-b in Figure 6). $T_{2}$ showed a decreasing trend, but the $\mathrm{H}_{2} \mathrm{O}$ adsorption capacity was increasing. $T_{2}$ reflects the degrees of freedom of the protons in the binding interactions between coal and water molecules, which was gradually increasing. The value of $T_{2}$ at 700 and $950^{\circ} \mathrm{C}$ shifted to the right (curve b-c in Figure 6), and the binding interactions of coal samples with adsorbed water molecules decreased. In the pyrolysis process, the oxygencontaining functional groups with weak binding interactions escaped first as the temperature increased. The residual binding interactions in coal were strong, and the absorption of water molecules was strong. However, the total amount of adsorption was reduced. Therefore, the maximum adsorption interactions of each coal sample increased first and then decreased, and this process was closely related to the evolution of oxygen-containing functional groups [20].

The distribution $T_{2}$ in the saturated water lignite samples was investigated (Figure 7 ). The $T_{2}$ values of the coal samples at 700 and $950^{\circ} \mathrm{C}$ significantly shifted to the right, indicating that the water molecule binding interactions in the coal samples were weak, and the relaxation times were long.

Meanwhile, the $T_{2}$ of the coal sample heated at $950^{\circ} \mathrm{C}$ shifted to the left relative to that of the coal sample heated at $700^{\circ} \mathrm{C}$, and there were significant peaks at relaxation times 




Figure 3: Thermogravimetry (TG) curves of $\mathrm{H}_{2} \mathrm{O}$ desorption of the thermally treated lignite samples after $\mathrm{H}_{2} \mathrm{O}$ adsorption.

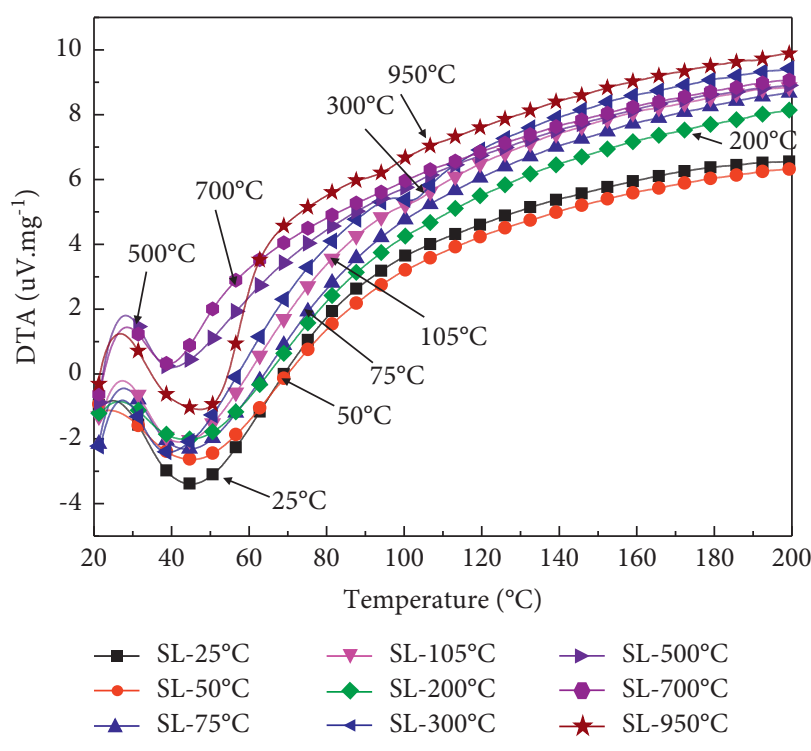

(a)

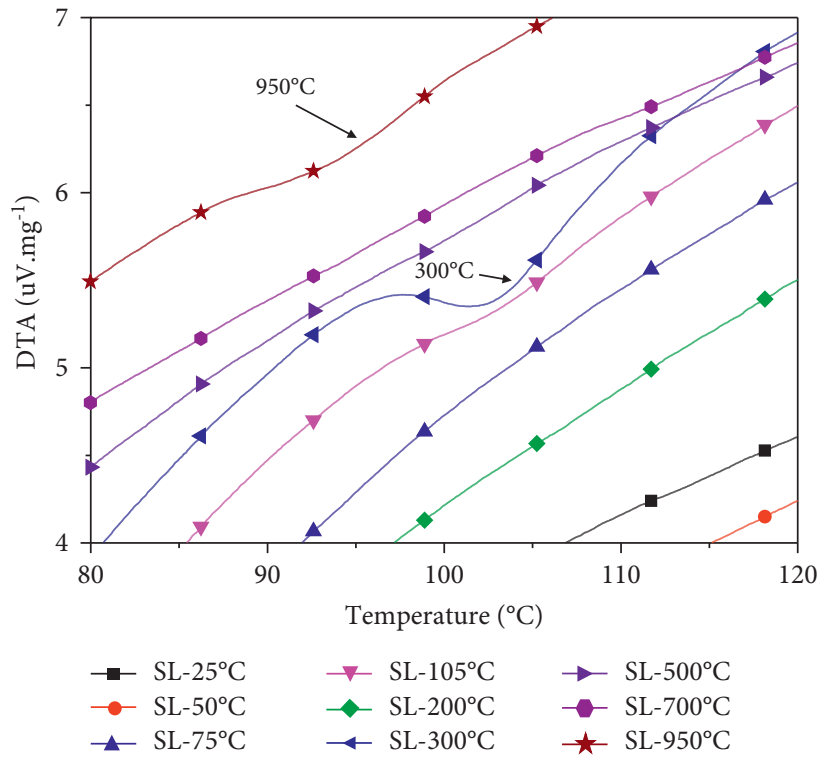

(b)

FIGURE 4: Desorption differential thermal analysis (DTA) curves of lignite and coke after adsorption.

between 0.2 and $0.5 \mathrm{~ms}$ (Figure $7(\mathrm{a}): B_{950}$ ). This indicated that the adsorption capacity of the coal sample heated at $950^{\circ} \mathrm{C}$ was different from that of the coal sample heated at $700^{\circ} \mathrm{C}$. The $T_{2}$ distribution in the adsorbed of lignite was investigated (Figure 7(b)). The peak of the coal sample heated at $950^{\circ} \mathrm{C}$ was significantly different from that of the coal sample heated at $700^{\circ} \mathrm{C}$ for relaxation times between 0.2 and $0.5 \mathrm{~ms}$ (Figure $7(\mathrm{~b}): B_{950}$ ). Based on these results and the ${ }^{1} \mathrm{H}-\mathrm{NMR}$ results described above, there were strong binding interactions in the coal sample heated at $950^{\circ} \mathrm{C}$, similar to that in the coal sample heated at $300^{\circ} \mathrm{C}$ (Figure 7).

The results of the ${ }^{1} \mathrm{H}-\mathrm{NMR}$ experiment and lignite coke absorption and desorption experiments had good consistency. With the increase in the heat-treatment temperature, the structure of the lignite coke changed at around 300 and $950^{\circ} \mathrm{C}$, which led to an enhanced binding effect of the lignite coke with some of the water molecules, a rise in the desorption temperature, and a relative increase in the amount of moisture adsorbed.

\subsection{Physical and Chemical Structure Changes during Lignite Pyrolysis}

3.3.1. Oxygen-Containing Functional Groups. Infrared analysis was used to detect the changes of the oxygencontaining functional groups in the lignite coke [21]. The 


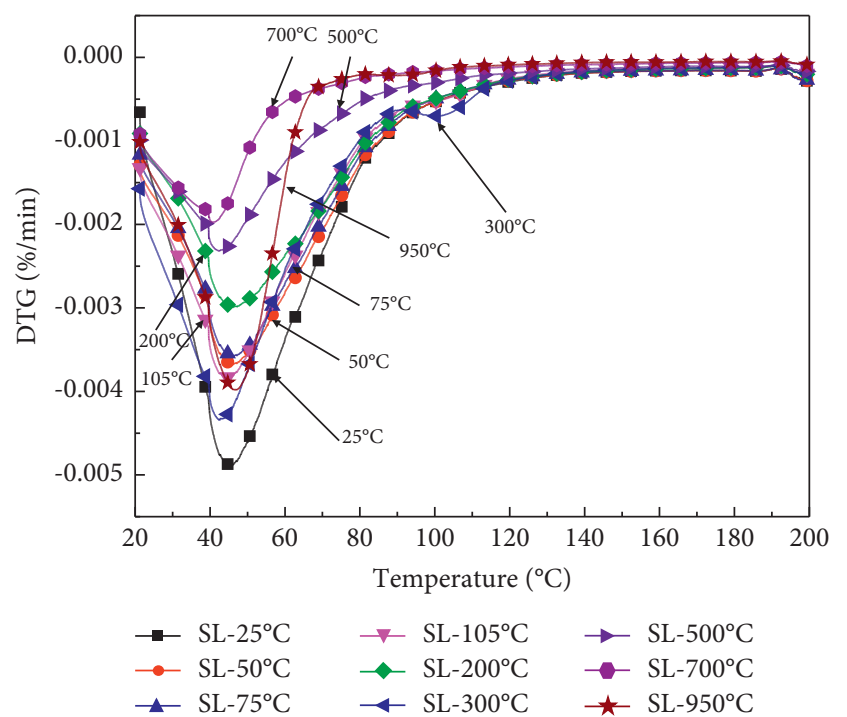

(a)

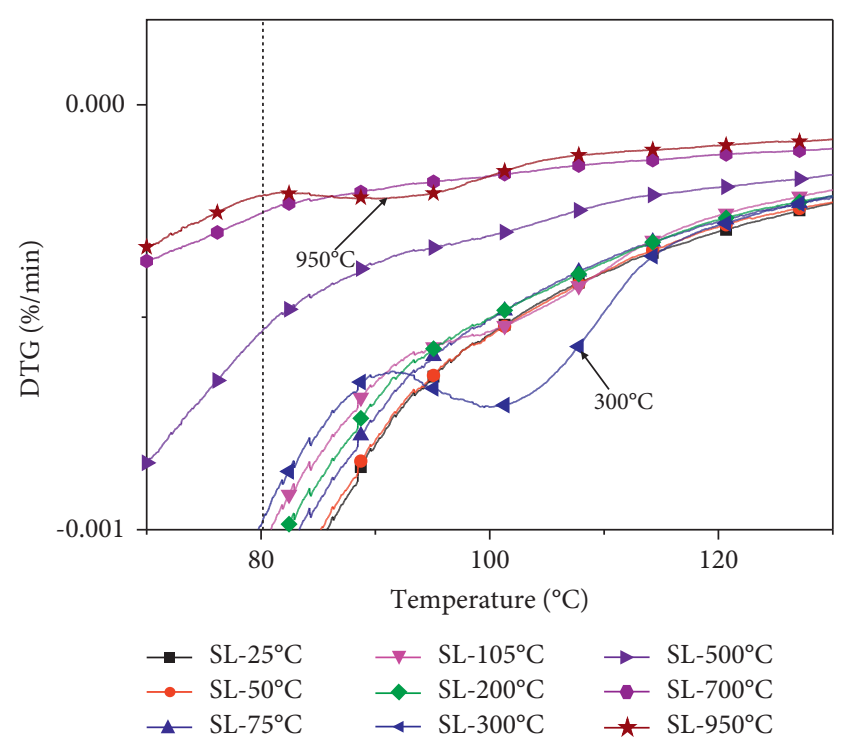

(b)

FIGURE 5: Desorption derivative thermogravimetry (DTG) curves of lignite and coke after adsorption.

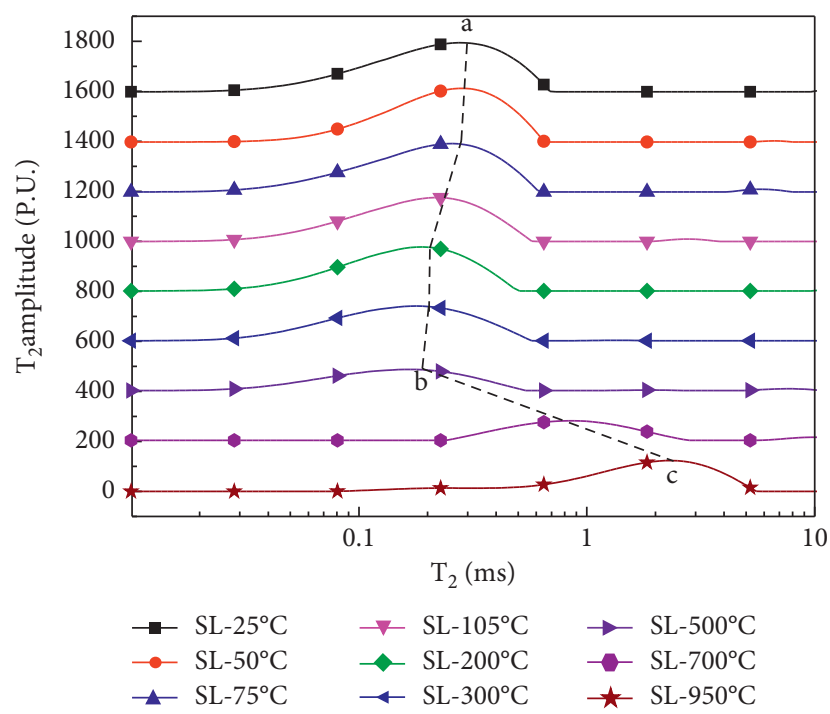

Figure 6: Coke adsorption capacities for $\mathrm{H}_{2} \mathrm{O}$ during different pyrolysis stages.

calculation of the content of oxygen-containing functional groups is shown in Supplementary Materials S1.

The oxygen-containing functional group content in the lignite increased first and then decreased (Figure 8), and the change of the water molecule adsorption quantity (Figures 1 and 2) was in good agreement. In particular, the ether bonds at 300 and $950^{\circ} \mathrm{C}$ were abnormal. In the pyrolysis process, the content of ether bonds generally showed a downward trend, but at 300 and $950^{\circ} \mathrm{C}$, the downward trend slowed and even changed to an upward trend (Figure $8(\mathrm{c}): A_{300}, B_{950}$ ), which was consistent with previous experimental results [22]. The moisture adsorption capacity of the 300 and $950^{\circ} \mathrm{C}$ lignite coke (Figure 1: $A_{300}, B_{950}$; Figure 2: $A_{300}, B_{950}$ ) was consistent with the changes of the ether bond content. This indicated that the increase in the ether bond contents in the coal samples at 300 and $950^{\circ} \mathrm{C}$ was an important reason for the increase of the adsorbed moisture in the coal coke.

Meanwhile, the ${ }^{1} \mathrm{H}-\mathrm{NMR}$ data showed that a small amount of moisture with strong adsorption was present in the lignite coke at 300 and $950^{\circ} \mathrm{C}$ (Figure 7), and there was also a small amount of moisture present during the process of water desorption, whose removal temperature was higher than that of the other water (Figures 3, 5, and 6). Based on the above analysis, the generation of ether bonds in the lignite coke at 300 and $950^{\circ} \mathrm{C}$ enhanced the binding of the lignite coke surface to some of the moisture.

3.3.2. Pore Size Distribution. The pore distributions of coal samples were determined by ${ }^{1} \mathrm{H}-\mathrm{NMR}$, and the pore size distribution is shown in Figure 9 and Table 3.

The microstructural evolution of the heat-treated lignite was further investigated using SEM (Figure 10). The lignite coke below the heat-treatment temperature of $200^{\circ} \mathrm{C}$ exhibited no chemical differences from the raw coal. With the removal of water in the pores, more pores were exposed, resulting in a significant increase in the pore content. When the heat-treatment temperature was higher than $200^{\circ} \mathrm{C}$, the heat-treatment process caused significant weight loss and gas escape [18]. In particular, condensation polymerization occurred at about $300^{\circ} \mathrm{C}$, resulting in ether bonds and pore contraction (Figure 10). Under $500^{\circ} \mathrm{C}$ heat treatment, the number of lignite coke pores increased (Table 3 and Figures 9 and 10). At this point, the bridge bond fracture reached its maximum value. The porosity of lignite coke treated at $700^{\circ} \mathrm{C}$ continued to increase (Table 3 and Figures 9 and 10), and it increased significantly, which was caused by condensation polymerization [23]. When the heat-treatment temperature was $950^{\circ} \mathrm{C}$, the proportion of pores below $10 \mathrm{~nm}$ was significantly reduced, and the pore size distribution 


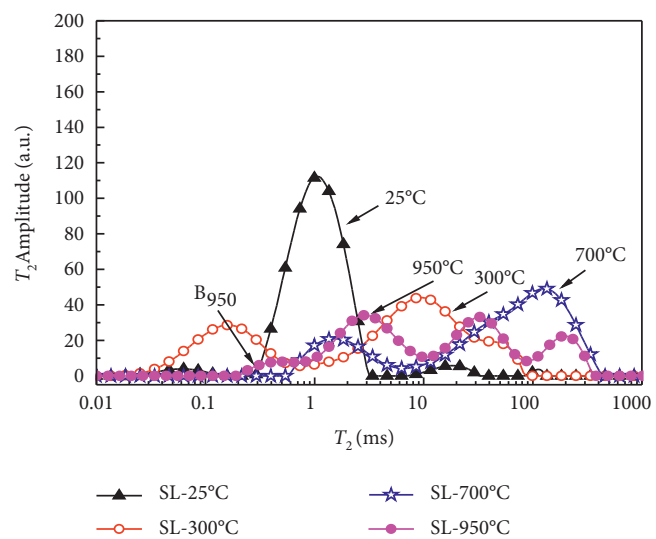

(a)

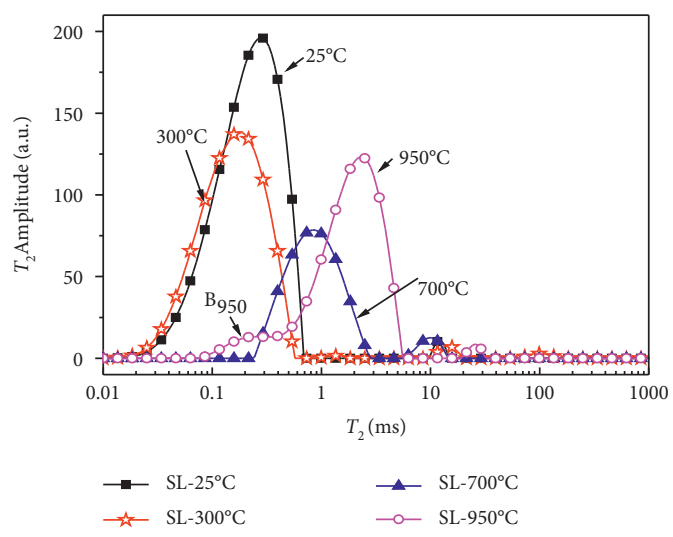

(b)

Figure 7: (a) $T_{2}$ distribution of thermally treated lignite saturated water. (b) $T_{2}$ distribution of $\mathrm{H}_{2} \mathrm{O}$ on adsorbed water sample.



(a)



(b)

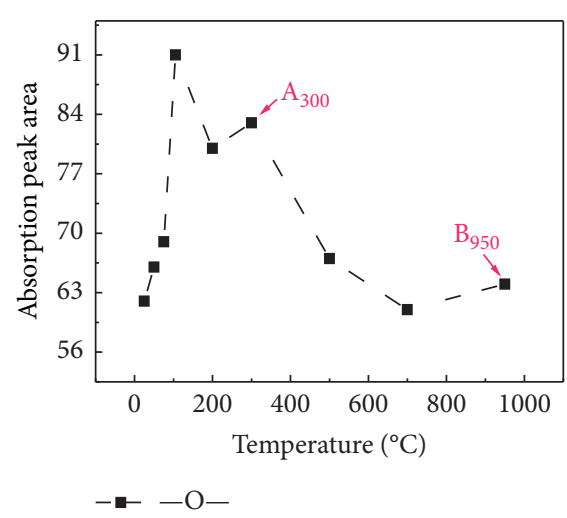

(c)

Figure 8: Absorption peak areas of (a) $-\mathrm{OH}$, (b) $\mathrm{C}=\mathrm{O}$, and (c) - $\mathrm{O}$ - groups of thermally treated lignite.

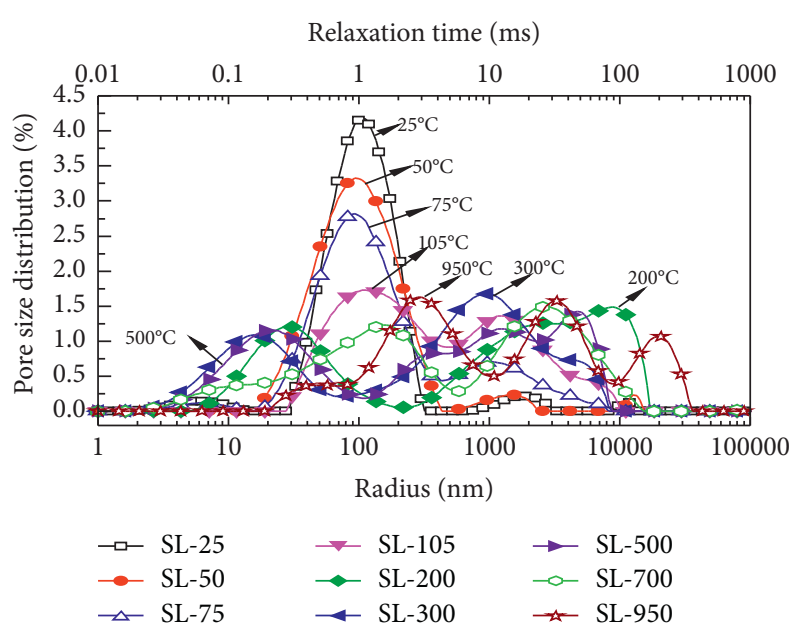

Figure 9: Pore size distribution of heat treatments of the coal samples at different temperatures from ${ }^{1} \mathrm{H}-\mathrm{NMR}$.

moved toward the direction of large pores, which also indicated that condensation polymerization and pore collapse occurred at this stage.
Based on the above changes of the amount of water molecule adsorption and the water binding state in the lignite coke, as well as the physical and chemical changes that occurred in the lignite coke heat-treatment process, it was inferred that the abnormal changes of the water molecule adsorption on the lignite coke heated at 300 and $950^{\circ} \mathrm{C}$ were caused by the formation of ether bonds and pore changes.

3.4. $\mathrm{H}_{2} \mathrm{O}$ Adsorption Mechanism of Lignite and Coke. According to above analysis and previous research [18], the water molecule adsorption mechanisms of lignite and coke were determined, and they are shown in Figure 11.

When the heat-treatment temperature was below $105^{\circ} \mathrm{C}$, with the increase in temperature, moisture escaped and oxygen-containing functional groups were exposed in the lignite. The number of active sites or oxygen-containing functional groups was the highest [18]. The moisture was absorbed on the active sites, which led to increased water molecule absorption in lignite in this temperature range. However, most of the absorbed water molecules were single layered. This was associated with a strong absorption force. 
TABLE 3: Different size pore ratios of lignite at different heat treatment temperatures $\left({ }^{1} \mathrm{H}-\mathrm{NMR}\right)$.

\begin{tabular}{lcccc}
\hline Temperature $\left({ }^{\circ} \mathrm{C}\right)$ & \multicolumn{3}{c}{ Pore ratios (\%) } \\
\hline 25 & $<10 \mathrm{~nm}$ & $10-100 \mathrm{~nm}$ & $100-1000 \mathrm{~nm}$ & 47.27 \\
50 & 2.51 & 46.74 & 41.38 & 3.48 \\
75 & 0.00 & 54.96 & 43.96 & 3.66 \\
105 & 2.08 & 40.75 & 47.41 & 13.21 \\
200 & 0.00 & 22.84 & 11.43 & 29.75 \\
300 & 1.52 & 31.00 & 32.94 & 36.05 \\
500 & 9.17 & 24.79 & 25.03 & 33.10 \\
700 & 6.55 & 29.81 & 31.53 & 49.61 \\
950 & 3.33 & 16.06 & 40.36 & 51.31 \\
\hline
\end{tabular}

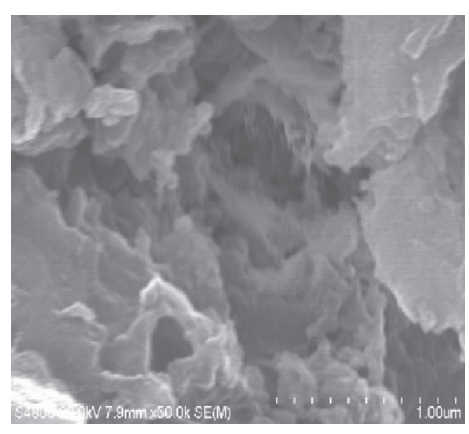

(a)

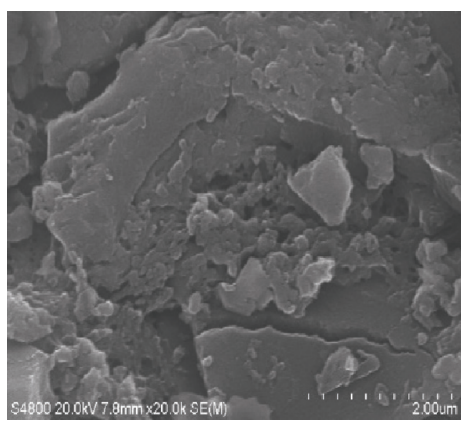

(c)

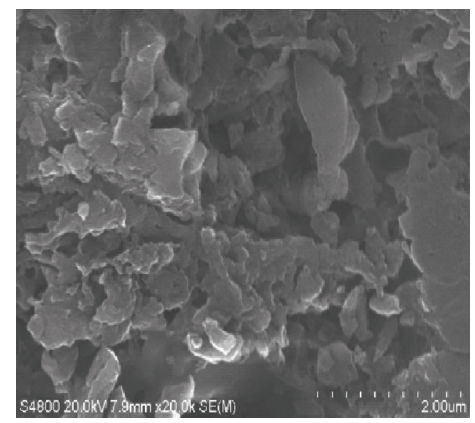

(b)

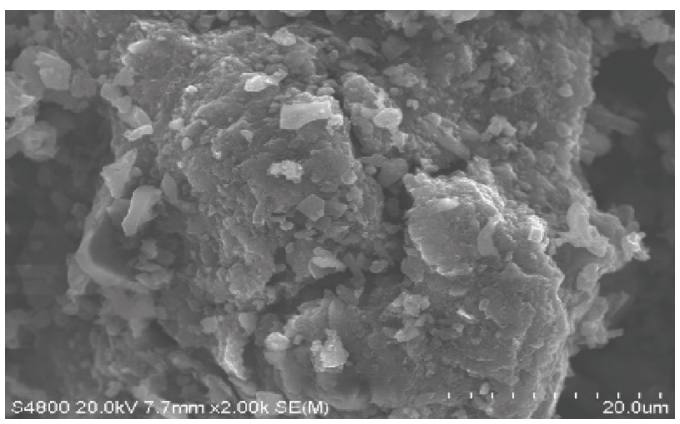

(d)

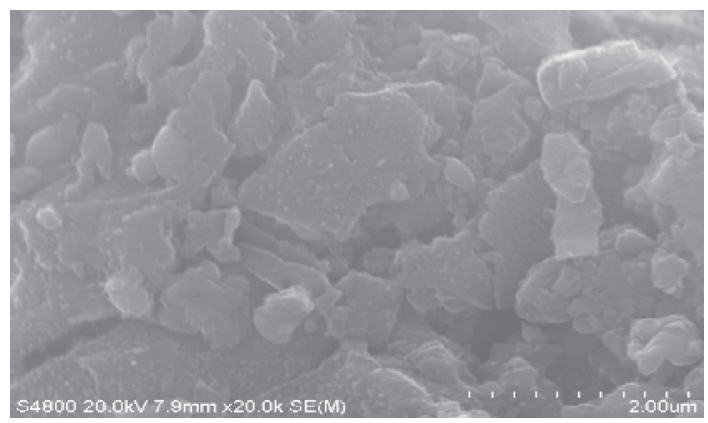

(e)

Figure 10: Scanning electron microscopy (SEM) images of lignite coke pyrolyzed at different temperatures: (a) $200^{\circ} \mathrm{C}$, (b) $300^{\circ} \mathrm{C}$, (c) $500^{\circ} \mathrm{C}$, (d) $700^{\circ} \mathrm{C}$, and (e) $950^{\circ} \mathrm{C}$.

The relaxation time $\left(T_{2}\right)$ decreased, and the pre $-105^{\circ} \mathrm{C}$ heat treatment of the coal sample moisture relaxation time decreased (Figure 6). When the heat-treatment temperature was $105-500^{\circ} \mathrm{C}$, the content of oxygen functional groups $-\mathrm{OH}$ and $\mathrm{C}=\mathrm{O}$ continued to decrease and the adsorbed moisture decreased with the increase in temperature. However, the bonding interactions of water molecules were relatively strong, with relaxation time decreasing (Figure 6). The increase in the ether bonds in the coal samples at $300^{\circ} \mathrm{C}$ slowed the decreasing trend of water molecule absorption 




(a)



(b)

Figure 11: Change of $\mathrm{H}_{2} \mathrm{O}$ adsorption due to lignite pyrolysis: (a) water molecule adsorption model on lignite surface and (b) adsorption model of water molecules in pores of lignite.

(Figures 1 and 2). The oxygen-containing functional groups $\left(\mathrm{OH}\right.$ and -O- ) of the coal samples heated at 500 and $700^{\circ} \mathrm{C}$ continued to decrease, and $\mathrm{C}=\mathrm{O}$ disappeared (Figure 8). As a result, an insufficient number of water molecules were adsorbed to form the first layer water. Significant multilayer water appears in $500^{\circ} \mathrm{C}$ coal samples (Figure 6). The amount of water absorption in the $500^{\circ} \mathrm{C}$ and $700^{\circ} \mathrm{C}$ coal samples was relatively small for all the coal samples, as the content of oxygen functional groups in those two samples was small (Figures 1 and 2). However, the $T_{2}$ of the lignite coke heated at $500^{\circ} \mathrm{C}$ was the shortest, and the adsorption force was the strongest (Figure 6). The coal sample heated at $950^{\circ} \mathrm{C}$ contained a certain number of ether bonds, and the water molecule absorption increased significantly (Figures 1 and 2 ). However, the maximum adsorption force was the weakest (Figure 6), because the functional groups were almost gone (Figure 8).

Through comprehensive consideration of the pore changes [18], it was found that the cracks were larger (Figures 7(a) and 9) and the multilayer water was not easy to retain. The moisture state of the coal sample heated at $700^{\circ} \mathrm{C}$ changed, and the amount of multilayer adsorption increased (Figure 7(b)). There should be a critical point between 500 and $700^{\circ} \mathrm{C}$ at which the moisture adsorption changes from a single layer to multiple layers (Figure 6). Although there was little $-\mathrm{OH}$ in $950^{\circ} \mathrm{C}$ coal samples, the $-\mathrm{O}$ - content increased (Figure 8). Meanwhile, large-aperture crannies disappeared (Figures 7(a) and 9), and the apertures $(20-1000 \mathrm{~nm}$ ) were uniformly distributed (Figures 7(a) and 9). As the numbers of $-\mathrm{OH}$ and -O- groups were relatively small (1000 and 63, respectively), there was less single-layer water, and most of the adsorbed water was multilayer. At the same time, owing to the well-distributed apertures compared to those of the coal sample treated at $700^{\circ} \mathrm{C}$, the multilayer water could be retained. As a result, the number of adsorbed water molecules of the coal sample heated at $950^{\circ} \mathrm{C}$ surpassed those of the samples heated at 700 and $500^{\circ} \mathrm{C}$ (Figures 1 and 2). The uniform distribution of pore diameters allowed the multilayer water to be retained, which was the body of the absorbed water (Figure 7(a)).

\section{Conclusion}

In summary, in this study, a new ${ }^{1} \mathrm{H}-\mathrm{NMR}$ method for studying the water molecule adsorption of lignite and coke was proposed. This method was used to explore the water absorption and desorption processes of lignite pyrolysis at different temperatures $\left(25-950^{\circ} \mathrm{C}\right)$ and the special contributions of ether bonds to the water adsorption. The adsorption was demonstrated to be dependent on the presence of "ether bonds" in the lignite pyrolysis process, which could significantly improve the adsorption effect of water. The increase in the ether bond content (at 300 and $950^{\circ} \mathrm{C}$ ) resulted in a significant increase in the water adsorption capacity and a significant decrease in the desorption capacity. The reason for this phenomenon was the strong adsorption capacities of the ether bonds. The ether bonds could cause water molecules to form stable adsorption layers in a monolayer water state. In the pyrolyzed coal samples at $950^{\circ} \mathrm{C}$, the adsorption capacities of the ether bonds remained high after the monolayer of water was saturated, and the water molecules underwent multilayer adsorption. This study offers a new approach for investigating the water molecule adsorption and the adsorption mechanism of lignite and coke.

\section{Data Availability}

The data used to support the findings of this study are available from the corresponding author upon request.

\section{Conflicts of Interest}

The authors declare that they have no direct financial relationship with the commercial entities mentioned in this study that might lead to conflicts of interest. 


\section{Acknowledgments}

This work was supported by grants from the National Natural Science Foundation of China (21766023), Science and Technology Program of Inner Mongolia (grant number 2019GG268), Research Project of Inner Mongolia University of Technology (grant number ZZ201906), Science and Technology Plan Project with Applied Technology Research and Development of Ordos (grant number 2019501), Science and Technology Development Fund of Central Guide Place in 2020 (grant number 2020ZY00322), and Scientific Research Project for Higher Education Institution of Inner Mongolia (grant number NJZY21150).

\section{Supplementary Materials}

As shown in Supplementary Materials S1, the FTIR spectra of the lignite samples treated under different temperatures exhibited the same shapes but showed different intensities of the absorption peaks. The peak at $1700 \mathrm{~cm}^{-1}$ is the stretching vibration peak of aromatic $\mathrm{C}=\mathrm{O}$, and the peak at $1600 \mathrm{~cm}^{-1}$ is the stretching vibration peak of aromatic $\mathrm{C}=\mathrm{C}$. The peak at $1110 \mathrm{~cm}^{-1}$ is the stretching vibration peak of -O-. The integral area was acquired by integrating the fitted FTIR spectra in the ranges of $3000-3700 \mathrm{~cm}^{-1}(-\mathrm{OH})$, $1550-1800 \mathrm{~cm}^{-1}(\mathrm{C}=\mathrm{O})$, and $1100-1200 \mathrm{~cm}^{-1}$ (-O-). (Supplementary Materials)

\section{References}

[1] Z. Miao, Y. Wan, Q. He, Z. Pei, and X. Zhu, "Pyrolysis behaviors and product distribution of shengli lignite at different heating rate and final temperature by TG-FTIR and Py-GCMS," Energy Sources Part A Recovery Utilization and Environmental Effects, vol. 43, no. 10, pp. 1-13, 2019.

[2] Y. Zhang, X. Zhang, Q. Zhong, S. Hu, and J. P. Mathews, "Structural differences of spontaneous combustion prone inertinite-rich Chinese lignite coals: insights from XRD, solidstate 13C NMR, LDIMS, and HRTEM," Energy \& Fuels, vol. 33, no. 5, pp. 4575-4584, 2019.

[3] S. Tao, S. Chen, D. Tang, X. Zhao, H. Xu, and S. Li, "Material composition, pore structure and adsorption capacity of lowrank coals around the first coalification jump: a case of eastern Junggar basin, China," Fuel, vol. 211, no. 1, pp. 804-815, 2018.

[4] S. Tao, X. Zhao, D. Tang, C. Deng, Q. Meng, and Y. Cui, "A model for characterizing the continuous distribution of gas storing space in low-rank coals," Fuel, vol. 233, no. 9, pp. 552-557, 2018.

[5] X. Men, S. Tao, Z. Liu, W. Tian, and S. Chen, "Experimental study on gas mass transfer process in a heterogeneous coal reservoir," Fuel Processing Technology, vol. 216, no. 1, pp. 1-9, 2021.

[6] Z. Huang, Y. Tian, Y. Gao, Z. Shao, Y. Zhang, and X. Liu, "Study on the oxidation kinetics and microreactivity of waterimmersed coal," ACS Omega, vol. 5, no. 28, pp. 17287-17303, 2020.

[7] J. B. Murray and D. G. Evans, "The brown-coal/water system: part 3. thermal dewatering of brown coal," Fuel, vol. 51, no. 4, pp. 290-296, 1972.

[8] J. A. Gutierrez-Rodriguez, R. J. Purcell Jr, and F. F. Aplan, "Estimating the hydrophobicity of coal," Colloids and Surfaces, vol. 12, no. 5, pp. 1-25, 1984.
[9] J. Liu, X. Jiang, Y. Cao et al., "Exploring the effect of oxygencontaining functional groups on the water-holding capacity of lignite," Journal of Molecular Modeling, vol. 24, no. 6, p. 130, 2018.

[10] H.-S. Kim, Y. Nishiyama, K. Ideta et al., "Analysis of water in loy yang brown coal using solid-state 1H NMR," Journal of Industrial and Engineering Chemistry, vol. 19, no. 5, pp. 1673-1679, 2013.

[11] J. Liao, Q. Mo, C. Li, Y. Han, L. Chang, and W. Bao, "Classification of water forms in lignite and analysis of energy consumption on the drying processes by microwave and fixed bed," Fuel, vol. 253, pp. 580-587, 2019.

[12] W. Yu, J. Yang, X. Wu et al., "Study on dewaterability limit and energy consumption in sewage sludge electro-dewatering by in-situ linear sweep voltammetry analysis," Chemical Engineering Journal, vol. 317, no. 8, pp. 980-987, 2017.

[13] F. Wei, J. Liao, L. Chang, Y. Han, and W. Bao, "Transformation of functional groups during lignite heat-treatment and its effects on moisture re-adsorption properties," Fuel Processing Technology, vol. 192, no. 2, pp. 210-219, 2019.

[14] L. Hu, G. Wang, and Q. Wang, "Efficient drying and oxygencontaining functional groups characteristics of lignite during microwave irradiation process," Drying Technology an International Journal, vol. 36, no. 10, pp. 1086-1097, 2018.

[15] K. Miura, K. Mae, W. Li, T. Kusakawa, F. Morozumi, and A. Kumano, "Estimation of hydrogen bond distribution in coal through the analysis of $\mathrm{OH}$ stretching bands in diffuse reflectance infrared spectrum measured by in-situ techniqueflectance infrared spectrum measured by in-situ technique," Energy \& Fuels, vol. 15, no. 3, pp. 599-610, 2001.

[16] S. K. Rish, A. Tahmasebi, and J. Yu, "A DSC study on the impact of low-temperature oxidation on the behavior and drying of water in lignite," Journal of Thermal Analysis and Calorimetry, vol. 139, no. 6, pp. 3507-3517, 2019.

[17] B. Lv, Z. Luo, B. Zhang, and C. Chen, "Drying and moisture readsorption characteristics of lignite," International Journal of Coal Preparation and Utilization, vol. 40, no. 10, pp. 712729, 2020.

[18] Y. Teng, S. Lian, Q. Liu et al., "Evolvement behavior of microstructure and $\mathrm{H}_{2} \mathrm{O}$ adsorption of lignite pyrolysis," Chinese Journal of Chemical Engineering, vol. 24, no. 6, pp. 803-810, 2016.

[19] W. Liu and X. Li, Nuclear Magnetic Resonance Logging, Petroleum Industry Press, Beijing, China, 2011.

[20] L. M. Duarte, P. R. Filgueiras, S. R. C. Silva et al., "Determination of some physicochemical properties in Brazilian crude oil by $1 \mathrm{H}$ NMR spectroscopy associated to chemometric approach," Fuel, vol. 181, no. 10, pp. 660-669, 2016.

[21] A. Tahmasebi, J. Yu, Y. Han, F. Yin, S. Bhattacharya, and D. Stokie, "Study of chemical structure changes of Chinese lignite upon drying in superheated steam, microwave, and hot air," Energy \& Fuels, vol. 26, no. 6, pp. 3651-3660, 2012.

[22] H. Qiu, Influence of Oxygen-Containing Functional Group Content on Moisture Regain and Pyrolysis Reactivity of Lignite, Taiyuan University of Technology, Taiyuan, China, 2013.

[23] J. Gao, Coal Pyrolysis, Coking and Coal Tar Processing, Chemical Industry Press, Beijing, China, 2010. 